\title{
Resilience changes in watershed systems: a new perspective to quantify long-term hydrological shifts under perturbations
}

Man Qi $^{\mathrm{a}}$, Meili Feng ${ }^{\mathrm{b}}$, Tao Sun ${ }^{\mathrm{a},{ }^{*}, \text { Wei Yang }}{ }^{\mathrm{a}}$

${ }^{a}$ State Key Laboratory of Water Environment Simulation, School of Environment,

Beijing Normal University, Beijing 100875, China

${ }^{\mathrm{b}}$ Department of Civil, Environmental and Mechanical Engineering, University of Trento, Via Mesiano, 77, 38123 Trento, Italy

* Corresponding author.

E-mail address: suntao@bnu.edu.cn (T. Sun). 


\section{Abstract}

Natural hydrological regimes are essential to the stability of river basins. While numerous efforts have been put forth to characterize flow regime alterations driven by climate change and human activities, few approaches have been proposed to explore changes in watershed resilience. The present study attempted to introduce a systematic approach that can be used to identify the resilience change of river basins based on annual river discharge through the application of a convex model and the principle of critical slowing down. Specifically, a resilience indicator $\left(p_{i}\right)$ that reflects streamflow autocorrelation at a given time was proposed to represent the temporal variation of the system resilience, and annual water discharge at representative hydrological stations located in upstream, midstream, and downstream regions of a river basin was used to reflect alterations in long-term hydrological processes and the stability of river basins. The application of this method to the Yellow River basin and Yangtze River basin indicated that the system resilience was lower in downstream regions compared to upstream regions. The Yellow River basin has suffered a decrease in resilience in its lower reaches since 1971, which extended to the middle reaches in 1987 and upper reaches in 1990. Similarly, recent observation of the resilience change in the Yangtze River basin indicated that resilience in its lower reaches has likely decreased since 2002, and this low resilience extended to the middle reaches in 2005 . Overall, our study presents a new method to predict potential decreases of resilience in complex large scale watershed systems where mechanistic insight is insufficient to build reliable basin-scale hydrological, climate, ecosystem 
integrated models.

\section{Keywords:}

critical slowing down; resilience indicator; convex model; hydrological regime shift; watershed systems

\section{Introduction}

At the global scale, watersheds are now suffering from severe perturbations due to both climate change and anthropogenic disturbances, and notable examples include the Amazon basin and the Mississippi River basin (Davidson et al., 2012; Kidder, 2006; Levine et al., 2016; Liu and Zheng, 2002). In the Amazon basin, which is the location of the world's largest rainforest, unprecedented deforestation has caused a series of changes at the local and regional scales that have involved alterations in energy and water cycles (Davidson et al., 2012). As a representative of the capacity of a watershed to absorb and recover from perturbations or disturbances (Folke et al., 2010; Hoque et al., 2012; Randhir, 2014; Wilson and Browning, 2012), watershed resilience and associated transitions in watershed systems has becomes a critical topic in river basin conservation and management (Davidson et al., 2012). In order to understand the vulnerability and resilience of river basins in the face of change, numerous studies have strived to improve knowledge of the linkages between natural variability, drivers of change, ecosystem responses, and feedbacks within a watershed system or its subsystems; these studies have employed both tendency analysis of perturbations and watershed structure(Costa et al., 2003; Zhang et al., 2014a; Zhao et al., 2015a) and process-based model simulations (Coe et al., 2002, 2011; Hu et al., 
2015; Levine et al., 2016). For example, Nemec et al. (2014) calculated watershed resilience with nine watershed structure properties, i.e. ecological variability, diversity, modularity, acknowledgement of slow variables, tight feedbacks, social capital, innovation, overlap in governance, and ecosystem services. Hirota et al. (2011) recognized forest, savanna, and treeless state as three distinct attractors and empirically reconstructed the basin of attraction through analyzing the response of the global tree abundance pattern to precipitation. Levine et al. (2016) predicted the stability of the Amazon rainforest to climate change with coupled vegetation-climate models. Furthermore, Cosens and Williams (2012) analyzed resilience mechanisms in the Amudarya River basin through an agent-based model.

The problems are that 1) while existing statistical analyses based on temporal variation tendency of hydrological sequences, climate sequences, and other anthropogenic events are able to quantify the hydrological alteration and its main contributors, and are also direct, efficient, and scale flexible. Yet they have much limitation in deducing necessary information on the vulnerability and resilience change of river basins over time; 2) process-based modeling approaches including hydrological models, climate change models, and ecological models, which typically have more clear structural relationships between each segment within the model, are promising for detecting resilience change, however, use of these model is associated with tradeoffs between structural complexity and outcome uncertainties due to the coarse or even incomplete representations of inner processes (Lewis et al., 2011; Malhi et al., 2009; Marengo, 2004; Marengo et al., 2008; Rammig et al., 2010). This 
shortcoming may enlarge the uncertainty of a simulated outcome and estimated tipping points when combining climate change, hydrological responses, and ecological feedbacks into one integrated model even if this is technically feasible. We believe that with progress in modeling, the uncertainties can be narrowed by elucidating a process-level understanding of key relationships (Clark et al., 2015, 2016; Fatichi et al., 2016), but we wonder if before that, there might be another way that can shed some light on how basin resilience responds and if the river basin is under transition.

As a phenomenon that connects diverse ecosystems, human activities, and atmospheric processes within a watershed, the water cycle is not only crucial in maintaining watershed health, but it is also vulnerable to climate change and excessive human activity (Milly et al., 2008; Ouyang et al., 2009; Sun and Feng, 2013; $\mathrm{Xu}$ et al., 2007; Zhao et al., 2012). Consequently, long-term river flow regimes (streamflow) are acknowledged to be the accumulated representation of the upstream hydrological cycle and thus are widely used to reflect the disturbance suffered by the upstream subcatchments (Belmar et al., 2013; Yang et al., 2008; Zhang et al., 2014b, 2015). In addition, with the acknowledgement of the complexity of watershed systems, preliminary attempts have been made to study hydrological systems with the application of complex network theory, and this had shed light on how best to employ systematic angles to study the connections and complexities of hydrological networks through spatiotemporal correlations of flow regimes (Jha et al., 2015; Sivakumar and Woldemeskel, 2015). 
The present study explores the usefulness of systematic theory for studying the stability and resilience of watershed systems that are naturally and anthropogenic disturbed. To this end, critical slowing down theory was introduced and we then proposed a resilience indicator $\left(p_{i}\right)$ to quantify the temporal variation in the resilience of a watershed system based on a convex model and critical slowing down features. Consequently, we applied the $p_{i}$ indicator to the Yellow River and Yangtze River basins to identify differences in the resilience trends between the river basins with different functions. The spatial and temporal variations in the resilience of each river basin was analyzed with the supplementation of background information on the perturbations that they experienced. This study provides an attempt to study watershed resilience. The reliable identification of watershed resilience alterations is important because such data can indicate the development orientation of a watershed, and if need be, the results can be sent as alarm signals to local water resource management organizations.

\section{Methodology}

\subsection{Background}

To describe the stability and resilience of complex systems, researchers have used conceptual models with the resilience intuitively expressed as the stability fate of a ball in a landscape of hills and valleys, which are also known as attraction basins (Figs. 1a and 1b) (Dakos et al., 2010; Peterson et al., 1998).

$<$ Fig. 1 >

Recent theoretical work has suggested that a critical slowing down, as measured by 
the increased autocorrelation of a state variable (Figs. 1e and 1f), can be a generic leading indicator of low resilience and an early warning signal for critical transitions, even when mechanistic insight is insufficient for reliable predictive models (Dakos et al., 2010, 2012b; Scheffer et al., 2009). This critical slowing down means that a system state variable will recover slowly from small perturbations in the vicinity of bifurcation points between two adjacent attraction basins (Figs. 1c and 1d). Such critical slowing down has been observed across an array of complex dynamic systems, such as those pertaining to ecosystems (Dakos and Bascompte, 2014; Dakos et al., 2010, 2012a; Wouters et al., 2015) climate (Dakos et al., 2008; Lenton, 2011; Lenton et al., 2012), medicine (Meisel et al., 2015; Trefois et al., 2015), and social-financial markets (Tan and Cheong, 2014).

\subsection{Indicator of system resilience based on a convex model}

Since a system state variable recovers slowly from small perturbations near the transition between two adjacent attraction basins, for the same observation frequency, more intermediate data, which are neglected in a high resilience state, can be recorded in a low resilience system (black points in Figs. 1c and 1d). Based on the convex model for a time-variant variable from Jiang et al. (2014), we built a convex set to show this calculation (Figs. 1e and 1f). For each $X(t) \sim X(t+\tau), \tau \in 1,2, \ldots, n$, most points were located around a centerline with a slope of 1 (dashed line in Figs. 1e and 1f), which constituted a set of $\Omega(X \mid i, \tau)$. The deviation of a point from the centerline was positively correlated with the difference between $x_{i+\tau}$ and $x_{\mathrm{i}}$. To quantify the 
neighboring points that deviated too much from $x_{\mathrm{i}}$ (red points in Figs. 1e and 1f), a convex set boundary was set (red lines in Figs. 1e and 1f). Finally, the $i$ and $i+\tau$ value for each outlier $\left(x_{\mathrm{i}}, x_{\mathrm{i}+\tau}\right)$ in each $X(t) \sim X(t+\tau)$ were counted and stored in a variable named Count.

The resilience of the system at time $i$ was reflected by the differences in $x_{i}$ and its neighboring points $\left\{x_{i-n}, \ldots, x_{i-2}, x_{i-1} x_{i+1}, x_{i+2}, \ldots, x_{i+n}\right\}, n \in N^{*}$, and $2 n$ was the number of neighboring points considered. Larger differences corresponded to a higher resilience. Thus, we proposed an indicator $p_{i}$ to count the number of adjacent points with a strong deviation from $x_{i}$, and this value reflects the resilience of a system at time $i$. The calculation proceeded as follows:

$$
D_{i}=\left\{x_{i-n}, \cdots, x_{i-2}, x_{i-1}, x_{i+1,} x_{i+2}, \cdots, x_{i+n}\right\}, n \in N^{*}
$$

and for $x_{j} \in D_{i}$,

$$
\begin{aligned}
& f_{i, j}=\left\{\begin{array}{ll}
1 & \left|x_{i}-x_{j}\right| \geq \varepsilon \\
0 & \left|x_{i}-x_{j}\right|<\varepsilon
\end{array}, \quad \varepsilon=0.5 \lambda\left(X_{\max }-X_{\min }\right)\right. \\
& p_{i}=\sum_{j=i-n}^{j=i+n} f_{i, j}
\end{aligned}
$$

where $\varepsilon$ is the threshold that determins if $x_{j}$ deviates too much from $x_{i} . X_{\max }$ and $X_{\min }$ are the maximum and minimum of the state variable $X$, respectively. $\lambda \in(0,1)$ and the value of $\lambda$ directly define the boundary of the convex set: $\lambda=0$ corresponds to an empty set and $\lambda=1$ corresponds to the largest convex set that includes all observation points inside. Here, we set $\lambda=0.75$, which means the area of the convex set was equal to $75 \%$ of the area of the largest convex set $(\lambda=1)$. The value 0.75 refers to previous hydrological analysis studies (Richter et al., 1996, 1997). 
To verify the reliability of $p_{i}$ as an indicator of the system resilience, we constructed two sequences to represent a state variable at different resiliences (Fig. 2). At a high resilience, state variable $H$ was represented by randomly generated pseudorandom values in the open interval $(2,5)$ from a standard uniform distribution. At a low resilience, a much more autocorrelated state variable $L$ was acquired by interpolating $H$ to a lower recovery rate. We calculated the $p_{i}$ of $H$ and $L$ for different $n(n=2,4,9)$ to verify the effectiveness of $p_{i}$ as an indicator of the resilience difference and to assess the effect of $n$ on $p_{i}$.

\section{$<$ Fig. 2>}

The $p_{i}$ for $H$ and $L$ reflected a positive relationship with $n$. When $n=2,4$, or 9 , the range of $p_{i}$ was $0-4,0-8$, and $0-18$, respectively. The temporal variation of $p_{i}$ was consistent for different $n$, though there might have been minor local distinctions. The major difference was related to the variation increase for larger $n$ (Figs. 3a and 3b). As for different state variables, a state variable with a higher recovery rate had a higher $p_{i}$ than one with a lower recovery rate (Fig. 3c), in agreement with our assumption.

\section{$<$ Fig. 3>}

\section{Case study}

The Yellow River and the Yangtze River are the two largest rivers in China. Because of their distinct locations and regional water requirements, they play vital yet quite different roles in the development and production of domestic resources.

The Yellow River is located in northern China, which belongs to a predominantly 
semiarid to arid region, but is a major rice production center. The Yellow River is the second longest river in China and the sixth longest in the world, with a drainage area of $752,443 \mathrm{~km}^{2}$. This river, accounts for $8.7 \%$ of the freshwater supply for the total Chinese population (YRCC, 2001) (Fig. 4). Like other rivers worldwide, the Yellow River basin has suffered from excessive human exploration activities. The first Yellow River dam, namely, the Sanmenxia Dam, was built in the early 1960s, and afterward, an additional 10 dams and 21 hydroelectric power stations were constructed (YRCC, 2001; Yu et al., 2013). The mid and downstream reaches are associated with increased water use for irrigation, which has resulted in strongly altered hydrological regimes and consequently high risks for impacts on ecosystem health (Sun et al., 2015; Tang et al., 2014; Yang et al., 2012).

The Yangtze River is the longest river in China, and its share of annual runoff amounts to $36 \%$ of the total river runoff in China, which is 20 times higher than the Yellow River runoff according to the Changjiang \& Southwest Rivers Water Resources Bulletin (2012) available from the Yangtze River Conservancy Commission of the Ministry of Water Resources (http://www.cjw.gov.cn/UploadFiles/zwzc/2015/7/2012szygb.pdf). The Three Gorges Dam and Gezhouba Dam are the two major dams on the Yangtze River. The Three Gorges Dam has the largest storage capacity of $3.93 \times 10^{10} \mathrm{~m}^{3}$, which is about $4.5 \%$ of the annual total discharge (Cai et al., 2013).

Dam construction and other similar short-term human activities can regulate the seasonal river flow regimes and produce consistent perturbations in flow at 
downstream hydrological stations. Such perturbations will increase the correlation of daily or seasonal water discharges between stations, so that the watershed resilience tendency may emerge on a longer time scale. Therefore, we chose to use the annual water discharge from three representative hydrological stations located in the upstream, midstream, and downstream regions of the river basins for the analyses; specifically, these stations were located at Lanzhou (1919-2013), Sanmenxia (1919-2013), and Lijin (1950-2013) within the Yellow River basin, and at Pingshan (1956-2011), Yichang (1950-2011), and Datong (1950-2011) within the Yangtze River basin (Fig. 5). The annual streamflow records from these stations were collected from the Rainwater National Information Network (http://xxfb.hydroinfo.gov.cn/), which maintains the station gauging records, the Yellow River Water Resource Bulletin from the Yellow River Conservancy Commission of the Ministry of Water Resources (http://www.yellowriver.gov.cn/other/hhgb/), the Changjiang \& Southwest Rivers Water Resources Bulletin from the Yangtze River Conservancy Commission of the Ministry of Water Resources (http://www.cjw.gov.cn/zwzc/bmgb/), and existing records published in the literature (Zhao et al., 2015a).

<ig. 4>

<Fig. 5>

\section{Results}

We chose $n=4$ to calculate the $p_{i}$ for the hydrological time series to highlight the change tendency by enlarging its variation range, which required a higher $n$, and to 
reduce the uncertainty caused by considering uncorrelated points, which was associated with a smaller $n$. Although the annual water discharges from the three gauge stations in the Yellow River basin were highly consistent, the resilience analysis revealed differences (Fig. 6). Among these three stations, Lijin had the lowest $p_{i}$, which means that the resilience of the lower reach was smaller than that of the upper and middle reaches. In addition, the resilience decreased over time, with $p_{i}$ equaling nearly zero since 1990, 1987, and 1971 for Lanzhou, Sanmenxia, and Lijin, respectively. Although short-duration phenomenon of $p_{i}$ equaling zero was observed around 1950 in the Yellow River basin, such long time period of low resilience state at each sub-basin have not occurred before. We should pay more attention to the potential for "critical slowing down" in the Yellow River basin, which may indicate that the Yellow River basin is experiencing a critical transition or even possibly shifting to another lower resilience state. The contributors for such shift will be discussed in the next section.

The $p_{i}$ analysis for the Yangtze River basin also showed that the resilience of the lower reaches was lower than that for the upper reaches. The $p_{i}$ showed a mixed upward and downward trend, with no decreasing trend over time before 2000. However after 2002, the resilience of the lower and middle reaches decreased successively over time, with $p_{i}$ equaling nearly zero staring in 2002 and 2005 for the Datong and Yichang stations, respectively (Fig. 7). We can conjecture that the middle and lower reaches of the Yangtze River basin might be experiencing a "critical slowing down" because such phenomenon of $p_{i}$ equaling zero was not observed in the 
Yangtze River basin before. Meanwhile, it is still hard to draw such conclusion confidently because short-duration phenomenon of $p_{i}$ equaling zero was once observed in pre-impact period (around 1950) in the Yellow River basin but didn't last long.

<Fig. 6>

$<$ Fig. 7 $>$

\section{Discussion}

In general, an autocorrelation analysis can be used to identify early warning signals of a nearby tipping point (Dakos et al., 2010, 2012b). Here, spatiotemporal correlations were analyzed to understand the resilience changes based on the following spatial correlations: Lanzhou versus Sanmenxia station data and Sanmenxia versus Lijin station data in the Yellow River basin (Fig. 8); and Pingshan station data versus Yichang station data and Yichang versus Datong station data in the Yangtze River basin (Fig. 9). The correlation between Lijin and Sanmenxia was slightly higher than that for Sanmenxia and Lanzhou, which means that the resilience in the lower reaches was slightly lower than that in the upper reaches. As for the Yangtze River basin, the whole hydrological sequences revealed no strong spatiotemporal correlation (Fig. 9), while an autocorrelation analysis revealed that the hydrological autocorrelation of Yichang and Datong increased after the change points detected above, which also was indicative of potentially decreased resilience in both the middle and lower reaches of the Yangtze River basin. 


\section{$<$ Fig. 8 $>$}

$<$ Fig. 9>

It is generally believed that both climate change and human activities are driving water regime shifts in the Yellow River basin (Liu et al., 2012; Zhao et al., 2015a).

Data from the Yellow River Water Resource Bulletin from the Yellow River Conservancy Commission of the Ministry of Water Resources (http://www.yellowriver.gov.cn/other/hhgb/) and the Changjiang \& Southwest Rivers Water Resources Bulletin (2012) from the Yangtze River Conservancy Commission of the Ministry of Water Resources (http://www.cjw.gov.cn/UploadFiles/zwzc/2015/7/2012szygb.pdf) were used to compare the surface water utilization and allocation in the Yangtze and Yellow rivers (Table 1). Although water consumption in the Yangtze River was 4-6 times higher than that in the Yellow River, the surface water consumption only accounted for $21 \%$ of the total amount of surface water in the Yangtze River, opposed to $64 \%$ for the Yellow River basin.

<Table 1>

Variation of the resilience indicator $\left(p_{i}\right)$ based on annual river discharges revealed that the Yellow River basin has changed gradually since the 1970s, especially in its lower reaches. From the information on climate change and water abstraction during the past half century (Fig. 10), we found that precipitation and temperature at diverse sub-basins presented consistent trends except for precipitation at the lower reaches. 
For the upper and middle reaches, declines in precipitation were observed from 1980 to 2005 along with continuous increases in temperatures from 1970 onward and dramatic increases in water abstraction from the 1950 s to 1990 s, which contributed to the decreased resilience of the upper and middle reaches from 1987 onward. For the lower reaches, where resilience change started to occur in 1970 , both the extreme drought from 1965 to 1970 and linear increases in water abstraction from 1965 to 1980 contributed to the declined resilience. In general, resilience changes may be taken as a cumulative result of previous perturbations, and the tendency change of the resilience indicator $\left(p_{i}\right)$ used in this study lagged behind the climate change and human perturbations in the Yellow River basin by almost 20 to 30 years.

\section{$\langle$ Fig. 10 $>$}

Since 2002, water-sediment modulation (WSM) has been performed annually in the waters of Sanmenxia Dam in the Yellow River basin to buffer the pool infilling and scour the elevated riverbeds; this is accomplished through short-term (often $<20$ days) high water discharges (Yu et al., 2013). In addition, ecological restoration projects have been implemented in the lower reaches by diverting the flow from the main stream to restoration areas (Qi et al., 2016). The analysis of the hydrological sequence for the Lijin station after 2002 revealed that even though the annual water discharge slightly increased (Fig. 5a), the resilience in the lower reaches still remained at a low level (Fig. 6) and did not respond strongly to the anthropogenic ecological restoration work. This might have been partially due to the insufficient extent of ecological restoration work, which did not meet the requirements for resilience recovery, and 
partially due to the time lag response of resilience.

In the Yangtze River basin, $p_{i}$ decreased to zero starting in 2002 and 2005 at the Datong and Yichang stations, respectively. However, there is still no definitive evidence proving that resilience has been altered in the river basin. Annual water discharge exhibited a non-significant decreasing trend with an average decreasing rate of $-0.141 \times 10^{9} \mathrm{~m} 3 / \mathrm{yr}$ in the lower reaches of the Yangtze River basin from 1953 to 2010, where discharge is mainly controlled by precipitation (71\%) and anthropogenic activity (29\%) (Zhao et al., 2015b). The long-term decreasing water discharge in the lower reach increases the possibility of "critical slowing down" in this region because "critical slowing down" might occur long after persisting perturbations as observed in the Yellow River basin.

It is worthwhile to mention that according to data from the Eastern, Middle, and Western Route Project Plannings from the Office of the South-to-North Water Diversion Project Commission of the State Council, the South-to-North Water Diversion Project (SNWDP) plans to divert $42.3 \times 10^{9} \mathrm{~m}^{3}$ of water annually from the Yangtze River to northern China starting in 2015, and this might aggravate the resilience decrease in the Yangtze River basin.

The application of the abovementioned method provides an efficient and direct way to assess watershed resilience; however similar to other studies that have introduced systematic theory to hydrology, these approaches are still at a stage of infancy. Incorporation of supplementary background information and hydrological models to provide mechanistic insight into watershed trends before a thorough change theory of 
a hydrological system is established is an important step to take. In addition, the selection of the hydrological sequence may also need to be pondered, since monthly streamflow data and daily streamflow data are typically highly manipulated in river basins where intensive water conservancy projects exist. Lastly, one needs to determine what type of hydrological sequence can best represent long-term flow regime alterations within a watershed, as this issue still needs to be resolved in further studies.

\section{Conclusions}

In this study, we proposed a resilience indicator $p_{i}$ to reflect the temporal change in the resilience of river basins based on a convex model and on the principle of critical slowing down. This new approach can be used to predict critical transitions in a complex watershed system, especially when mechanistic insight is insufficient for reliable basin-scale climate, hydrological, and ecological models. The application of this method to the Yellow River basin and the Yangtze River basin revealed lower level of resilience in the downstream reaches compared to the upper reaches. In addition to precipitation declines due to climate change, the changes in the middle and lower reaches of the Yellow River basin might have also been caused by severe water use change, which disturbed the natural hydrological processes and connectivity of the basin. Its resilience decreased dramatically over time, and this trend started in the lower reaches and then extended to the whole basin until reaching a critical point; such changes will have to be addressed in the future to protect the basin. Specifically, 
the resilience changes of the Yellow River basin should be used as an early warning for water resource management organizations. The Yangtze River basin has also experienced a potential decrease of resilience in the middle and lower reaches since 2002, although only short-term "critical slowing down" was detected. In summary, the proposed resilience indicator $p_{i}$ was found to be useful for tentative explorations of watershed resilience change. In the future, additional information about resilience alterations, such as accurate assessments of tipping points, reversibility of watershed, and so forth, would be valuable in the Yellow River and Yangtze River basin. Moreover, this information could be further applied in process explicit modeling approaches in the future.

\section{Acknowledgements}

This study was funded by the National Basic Research Program of China (973) (2013CB430402), the National Science Foundation for Innovative Research Group (No. 51121003), the National Natural Science Foundation of China (No. 51279007), and the Fundamental Research Funds for the Central Universities.

\section{References}

Belmar, O., Velasco, J., Gutierrez-Canovas, C., Mellado-Diaz, A., Millan, A., Wood, P.J., 2013b. The influence of natural flow regimes on macroinvertebrate assemblages in a semiarid Mediterranean basin. Ecohydrology 6(3), 363-379. DOI:10.1002/eco.1274

Cai, W., Zhang, L., Zhu, X., Zhang, A., Yin, J., Wang, H., 2013. Optimized reservoir 
operation to balance human and environmental requirements: A case study for the Three Gorges and Gezhouba Dams, Yangtze River basin, China. Ecol. Inform. 18, 40-48. DOI:10.1016/j.ecoinf.2013.06.009

Clark, M.P. et al., 2015. Improving the representation of hydrologic processes in Earth System Models. Water Resour. Res., 51(8): 5929-5956.

Clark, M.P. et al., 2016. Improving the theoretical underpinnings of process - based hydrologic models. Water Resour. Res.

Coe, M., Latrubesse, E., Ferreira, M., Amsler, M., 2011. The effects of deforestation and climate variability on the streamflow of the Araguaia River, Brazil. Biogeochemistry 105(1-3), 119-131. DOI:10.1007/s10533-011-9582-2

Coe, M.T., Costa, M.H., Botta, A., Birkett, C., 2002. Long - term simulations of discharge and floods in the Amazon Basin. J. Geophys. Res. Atmos. 107(D20), LBA 11-1-LBA 11-17. DOI: 10.1029/2001JD000740

Cosens, B.A., Williams, M.K., 2012. Resilience and water governance: adaptive governance in the Columbia River basin. Ecol. Soc. 17(14), 3.

Costa, M.H., Botta, A., Cardille, J.A., 2003. Effects of large-scale changes in land cover on the discharge of the Tocantins River, Southeastern Amazonia. J. Hydrol. 283(1), 206-217. DOI:10.1016/S0022-1694(03)00267-1

Dakos, V., Bascompte, J., 2014. Critical slowing down as early warning for the onset of collapse in mutualistic communities. P. Natl. Acad. Sci. U. S. A. 111(49), 17546-17551. DOI:10.1073/pnas.1406326111

Dakos, V., Carpenter, S.R., Brock, W.A., Ellison, A.M., Guttal, V., Ives, A.R., Kefi, S., 
Livina, V., Seekell, D.A., van Nes, E.H., Scheffer, M., 2012a. Methods for detecting early warnings of critical transitions in time series illustrated using simulated ecological data. Plos One 7(7). DOI:10.1371/journal.pone.0041010

Dakos, V., Scheffer, M., van Nes, E.H., Brovkin, V., Petoukhov, V., Held, H., 2008. Slowing down as an early warning signal for abrupt climate change. P. Natl. Acad. Sci. U. S. A. 105(38), 14308-14312. DOI:10.1073/pnas.0802430105

Dakos, V., van Nes, E.H., D'Odorico, P., Scheffer, M., 2012b. Robustness of variance and autocorrelation as indicators of critical slowing down. Ecology 93(2), 264-271. DOI: $10.1890 / 11-0889.1$

Dakos, V., van Nes, E.H., Donangelo, R., Fort, H., Scheffer, M., 2010. Spatial correlation as leading indicator of catastrophic shifts. Theor. Ecol-Neth. 3(3), 163-174. DOI:10.1007/s12080-009-0060-6

Davidson, E.A. et al., 2012. The Amazon Basin in transition. Nature 481(7381), 321-328. DOI:10.1038/nature10717

Fatichi, S. et al., 2016. An overview of current applications, challenges, and future trends in distributed process-based models in hydrology. J. Hydrol. 537: 45-60.

Folke, C. et al., 2010. Resilience thinking: integrating resilience, adaptability and transformability. Ecol. Soc. 15(4): 20.

Hirota, M., Holmgren, M., Van Nes, E.H., Scheffer, M., 2011. Global resilience of tropical forest and savanna to critical transitions. Science 334(6053), 232-235. DOI:10.1126/science. 1210657

Hoque, Y.M., Tripathi, S., Hantush, M.M., Govindaraju, R.S., 2012. Watershed 
reliability, resilience and vulnerability analysis under uncertainty using water quality data. J. Environ. Manage. 109: 101-112. DOI:http://dx.doi.org/10.1016/j.jenvman.2012.05.010

Hu, Z., Wang, L., Wang, Z., Hong, Y., Zheng, H., 2015. Quantitative assessment of climate and human impacts on surface water resources in a typical semi-arid watershed in the middle reaches of the Yellow River from 1985 to 2006. Int. J. Climatol. 35(1), 97-113. DOI:10.1002/joc.3965

Huang, Y., Cai, J., Yin, H., Cai, M., 2009. Correlation of precipitation to temperature variation in the Huanghe River (Yellow River) basin during 1957-2006. J. Hydrol. 372(1), 1-8. DOI:10.1016/j.jhydrol.2009.03.029

Jha, S.K., Zhao, H., Woldemeskel, F.M., Sivakumar, B., 2015. Network theory and spatial rainfall connections: An interpretation. J. Hydrol. 527(0), 13-19. DOI:http://dx.doi.org/10.1016/j.jhydrol.2015.04.035

Jiang, C., Ni, B., Han, X., Tao, Y., 2014. Non-probabilistic convex model process: A new method of time-variant uncertainty analysis and its application to structural dynamic reliability problems. Comput. Method. Appl. M. 268, 656-676. DOI:10.1016/j.cma.2013.10.016

Kidder, T.R., 2006. Climate change and the Archaic to Woodland transition (3000-2500 cal BP) in the Mississippi River basin. Amer. Antiquity 71(2), 195-231. DOI:10.2307/40035903

Lenton, T.M., 2011. Early warning of climate tipping points. Nat. Clim. Change 1(4), 201-209. DOI:10.1038/nclimate1143 
Lenton, T.M., Livina, V.N., Dakos, V., Scheffer, M., 2012. Climate bifurcation during the last deglaciation? Clim. Past 8(4), 1127-1139. DOI:10.5194/cp-8-1127-2012

Levine, N.M. et al., 2016. Ecosystem heterogeneity determines the ecological resilience of the Amazon to climate change. P. Natl. Acad. Sci. U. S. A. 113(3), 793-797. DOI:10.1073/pnas.1511344112

Lewis, S.L., Brando, P.M., Phillips, O.L., van der Heijden, G.M., Nepstad, D., 2011. The 2010 Amazon drought. Science 331(6017), 554-554. DOI: 10.1126/science. 1200807

Liu, C., Zheng, H., 2002. Hydrological cycle changes in China's large river basin: the Yellow River drained dry, Climatic change: Implications for the hydrological cycle and for water management. Springer, pp. 209-224.

Liu, F., Chen, S., Dong, P., Peng, J., 2012. Spatial and temporal variability of water discharge in the Yellow River basin over the past 60 years. J. Geogr. Sci. 22(6), 1013-1033. DOI:10.1007/s11442-012-0980-8

Malhi, Y. et al., 2009. Exploring the likelihood and mechanism of a climate-change-induced dieback of the Amazon rainforest. P. Natl. Acad. Sci. U. S. A. 106(49), 20610-20615. DOI: 10.1073/pnas.0804619106

Marengo, J., 2004. Interdecadal variability and trends of rainfall across the Amazon Basin. Theor. Appl. Climatol. 78(1-3), 79-96. DOI:10.1007/s00704-004-0045-8

Marengo, J.A., Nobre, C.A., Tomasella, J., Cardoso, M., Oyama, M., 2008. Hydro-climatic and ecological behaviour of the drought of Amazonia in 2005. Philos. Trans. R. Soc. London, Ser. B. 363(1498), 1773-1778. 
DOI:10.1098/rstb.2007.0015

Meisel, C., Klaus, A., Kuehn, C., Plenz, D., 2015. Critical slowing down governs the transition to neuron spiking. PLoS Comput. Biol. 11(2), e1004097-e1004097. DOI:10.1371/journal.pcbi.1004097

Milly, P.C.D. et al., 2008. Stationarity Is Dead: Whither Water Management? Science 319(5863): 573-574. DOI:10.1126/science.1151915

Nemec, K.T. et al., 2014. Assessing Resilience in Stressed Watersheds. Ecol. Soc., 19(1). DOI:10.5751/ES-06156-190134

Ouyang, W., Skidmore, A.K., Hao, F., Toxopeus, A.G., Abkar, A., 2009. Accumulated effects on landscape pattern by hydroelectric cascade exploitation in the Yellow River basin from 1977 to 2006. Landscape Urban Plan. 93(3-4), 163-171. DOI:http://dx.doi.org/10.1016/j.landurbplan.2009.07.001

Peterson, G., Allen, C.R., Holling, C.S., 1998. Ecological Resilience, Biodiversity, and Scale. Ecosystems 1(1), 6-18. DOI:10.1007/s100219900002

Qi, M., Sun, T., Zhan, M., Xue, S., 2016. Simulating dynamic vegetation changes in a tidal restriction area with Relative Stress Tolerance Curves. Wetlands, 36 (Suppl 1), S31-S43. DOI:10.1007/s13157-015-0639-1

Rammig, A. et al., 2010. Estimating the risk of Amazonian forest dieback. New Phytol. 187(3), 694-706. DOI:10.1111/j.1469-8137.2010.03318.x

Randhir, T.O., 2014. Resilience of watershed systems to climate change. J. Earth Sci. Clim. Change 5: e109. DOI:10.4172/2157-7617.1000e109

Richter, B., Baumgartner, J., Wigington, R., Braun, D., 1997. How much water does a 
river need? $\quad$ Freshwater $\quad$ Biol. $37(1): \quad$ 231-249. DOI:10.1046/j.1365-2427.1997.00153.x

Richter, B.D., Baumgartner, J.V., Powell, J., Braun, D.P., 1996. A method for assessing hydrologic alteration within ecosystems. Conserv. Biol. 10(4): 1163-1174. DOI:10.1046/j.1523-1739.1996.10041163.x

Scheffer, M., Bascompte, J., Brock, W.A., Brovkin, V., Carpenter, S.R., Dakos, V., Held, H., van Nes, E.H., Rietkerk, M., Sugihara, G., 2009. Early-warning signals for critical transitions. Nature 461(7260), 53-59. DOI:10.1038/nature08227

Sivakumar, B., Woldemeskel, F.M., 2015. A network-based analysis of spatial rainfall $\begin{array}{llll}\text { connections. } & \text { Environ. } & \text { Modell. } & \text { Softw. }\end{array}$ DOI:http://dx.doi.org/10.1016/j.envsoft.2015.02.020

Sun, T., Feng, M.L., 2013. Multistage analysis of hydrologic alteration in the Yellow River, China. River Res. Appl. 29(8), 991-1003. DOI:10.1002/rra.2586

Sun, T., Zhang, H.Y., Yang, Z.F., Yang, W., 2015. Environmental flow assessments for transformed estuaries. J. Hydrol. 520, 75-84. DOI:10.1016/j.jhydrol.2014.11.015

Tan, J.P.L., Cheong, S.A., 2014. Critical slowing down associated with regime shifts in the US housing market. Eur. Phys. J. B 87(2). DOI:10.1140/epjb/e2014-41038-1

Tang, S., Sun, T., Shen, X., Qi, M., Feng, M., 2015. Modeling net ecosystem metabolism influenced by artificial hydrological regulation: An application to the Yellow River Estuary, China. Ecol. Eng. 76, 84-94. DOI:10.1016/j.ecoleng.2014.04.025

Trefois, C., Antony, P.M.A., Goncalves, J., Skupin, A., Balling, R., 2015. Critical 
transitions in chronic disease: transferring concepts from ecology to systems medicine. Curr. Opin. Biotech. 34(0), 48-55. DOI: http://dx.doi.org/10.1016/j.copbio.2014.11.020

Wilson, M.A., Browning, C.J., 2012. Investing in natural infrastructure: restoring watershed resilience and capacity in the face of a changing climate. Ecol. Restor. 30(2): 96-98.

Wouters, N., Dakos, V., Edwards, M., Serafim, M.P., Valayer, P.J., Cabral, H.N., 2015. Evidencing a regime shift in the North Sea using early-warning signals as indicators of critical transitions. Estuar. Coast. Shelf Sci. 152, 65-72. DOI:10.1016/j.ecss.2014.10.017

Xu, C., Liu, M., Zhang, C., An, S., Yu, W., Chen, J., 2007. The spatiotemporal dynamics of rapid urban growth in the Nanjing metropolitan region of China. Landscape Ecol. 22(6), 925-937. DOI:10.1007/s10980-007-9079-5

Yang, Y.-C.E., Cai, X., Herricks, E.E., 2008. Identification of hydrologic indicators related to fish diversity and abundance: A data mining approach for fish community analysis. Water Resour. Res. 44(4). DOI:10.1029/2006wr005764

Yang, Z., Yan, Y., Liu, Q., 2012. Assessment of the flow regime alterations in the Lower Yellow River, China. Ecol. Inform. 10, 56-64. DOI:10.1016/j.ecoinf.2011.10.002

YRCC (Yellow River Conservancy Commission), 2001. Yellow River in the 20th century (in Chinese). Yellow River Water Utilization Publisher, Zhengzhou, China. Yu, Y., Wang, H., Shi, X., Ran, X., Cui, T., Qiao, S., Liu, Y., 2013. New discharge 
regime of the Huanghe (Yellow River): Causes and implications. Cont. Shelf Res. 69, 62-72. DOI:10.1016/j.csr.2013.09.013

Zhang, Q., Gu, X., Singh, V.P., Xiao, M., 2014a. Flood frequency analysis with consideration of hydrological alterations: Changing properties, causes and implications. J. Hydrol. 519, 803-813. DOI:10.1016/j.jhydrol.2014.08.011

Zhang, Q., Gu, X., Singh, V.P., Xiao, M., Chen, X., 2015. Evaluation of flood frequency under non-stationarity resulting from climate indices and reservoir indices in the East River basin, China. J. Hydrol. 527: 565-575. DOI:http://dx.doi.org/10.1016/j.jhydrol.2015.05.029

Zhang, X., Fan, D., Wang, H., Yang, Z., 2014b. Water discharge variability of Changjiang (Yangtze) and Huanghe (Yellow) Rivers and its response to climatic changes. Chin. J. Oceanol. Limnol. 32(6), 1392-1405. DOI:10.1007/s00343-015-4034-9

Zhao, G. et al., 2015a. Changing trends and regime shift of streamflow in the Yellow River basin. Stoch. Env. Res. Risk A. 29(5): 1331-1343. DOI:10.1007/ s00477-015-1058-9

Zhao, Q., Liu, S., Deng, L., Dong, S., Cong, Wang, Yang, Z., Yang, J., 2012. Landscape change and hydrologic alteration associated with dam construction. Int. J. Appl. Earth Obs. 16, 17-26. DOI:10.1016/j.jag.2011.11.009

Zhao, Y. et al., 2015b. Quantifying the anthropogenic and climatic contributions to changes in water discharge and sediment load into the sea: A case study of the Yangtze River, China. Sci. Total Environ. 536, 803-812. 
DOI:http://dx.doi.org/10.1016/j.scitotenv.2015.07.119 


\section{Figure captions}

Fig. 1. Conceptual scheme of the resilience and stability of a complex system. A system dynamics is represented by a landscape and its state is expressed by a ball pulled into pits (a and b), with different topographies at different states of the system. The stability of a state is determined by the slope of the landscape at its present position, while its resilience corresponds to the width of the attraction basin in which the system currently is. At a high resilience state (c and $\mathbf{e}$ ), the high recovery rate can counterbalance small disturbances of the equilibrium, so that the time series of a state variable is characterized by a low correlation with subsequent values. At a low resilience state ( $\mathbf{d}$ and $\mathbf{f}$ ), the attraction basin shrinks and the system is closer to its tipping point. Small disturbances are not effectively buffered because of the low recovery rate and will increase the probability that the system will move to an alternative basin. Thus, the corresponding time series of the state variable is highly autocorrelated.

Fig. 2. Constructed sequences to verify the reliability of the resilience indicator $p_{i}$; a shows the time series of $H$ and $L$, which represent the high recovery rate at a high resilience and the low recovery rate at a low resilience, respectively, and $\mathbf{b}$ and $\mathbf{c}$ show the lag-1 autocorrelation of $H$ and $L$, respectively.

Fig. 3. Resilience indicator $p_{i}$ for the state variables $H$ and $L$, which represent the high recovery rate at a high resilience and the low recovery rate at a low resilience, respectively; $\mathbf{a}$ and $\mathbf{b}$ reflect the temporal variation of $p_{i}$ for different $n$, and $\mathbf{c}$ shows a comparative analysis of $p_{i}$ for $H$ and $L$. 
Fig. 4. Location of the two main Chinese rivers (blue lines) and gauge stations (black dots) selected for analyses.

Fig. 5. Annual water discharge from the Lanzhou, Sanmenxia, and Lijin hydrological time series in the Yellow River basin (a), and from the Pingshan, Yichang, and Datong hydrological time series in the Yangtze River basin (b).

Fig. 6. Temporal changes in the resilience indicator $p_{i}$ for the three gauge stations in the Yellow River basin.

Fig. 7. Temporal changes in the resilience indicator $p_{i}$ for the three gauge stations in the Yangtze River basin.

Fig. 8. Spatiotemporal correlation of the hydrological time series for the Yellow River basin, where $\mathbf{a}$ and $\mathbf{b}$ show the spatial correlation of the hydrological sequence for Sanmenxia versus Lanzhou, and Lijin versus Sanmenxia, respectively, with linear fitting used to represent the correlation between the two hydrological sequences; $\mathbf{c}-\mathbf{e}$ reflect the temporal autocorrelation of the hydrological sequences for the lag-1 at Lanzhou, Sanmenxia, and Lijin. The black and red dots represent, respectively, the autocorrelation before and after the time node identified as the dramatic change in the system resilience.

Fig. 9. Spatiotemporal correlation of the hydrological time series from the Yangtze River basin, where $\mathbf{a}$ and $\mathbf{b}$ show the spatial correlation of the hydrological sequences from Yichang versus Pingshan, and Yichang versus Datong, respectively, with linear fittings used to represent the correlation between the two hydrological sequences; $\mathbf{c}-\mathbf{e}$ reflect the temporal autocorrelation of the hydrological sequences for the lag-1 at 
Pingshan, Yichang, and Datong.

Fig.10. Annual precipitation (a), temperature (b) and water abstraction (c and $\mathbf{d}$ ) in the upper, middle and lower reaches of the Yellow River basin. Data were taken from Huang et al., 2009, Liu et al., 2012, and the Yellow River Water Resources Bulletins published by the Yellow River Conservancy Commission (http://www.yellowriver.gov.cn/other/hhgb/). 
Table 1. Water resource utilization and allocation in the Yangtze and Yellow Rivers (in $10^{9} \mathrm{~m}^{3}$ ).

\begin{tabular}{ccccc}
\hline Location & $\begin{array}{c}\text { Surface Water } \\
\text { Resources }\end{array}$ & $\begin{array}{c}\text { Surface } \\
\text { Water } \\
\text { Consumption }\end{array}$ & $\begin{array}{c}\text { Agriculture } \\
\text { Irrigation } \\
\text { Consumption }\end{array}$ & $\begin{array}{c}\text { Total } \\
\text { Impoundage }\end{array}$ \\
\hline Yangtze River & $916.51 \pm 131.31$ & $195.94 \pm 5.14$ & $97.36 \pm 2.07$ & $125.29 \pm 22.98$ \\
Yellow River & $48.22 \pm 7.36$ & $30.90 \pm 1.54$ & $23.00 \pm 0.86$ & $34.61 \pm 3.73$ \\
\hline
\end{tabular}


high resilience

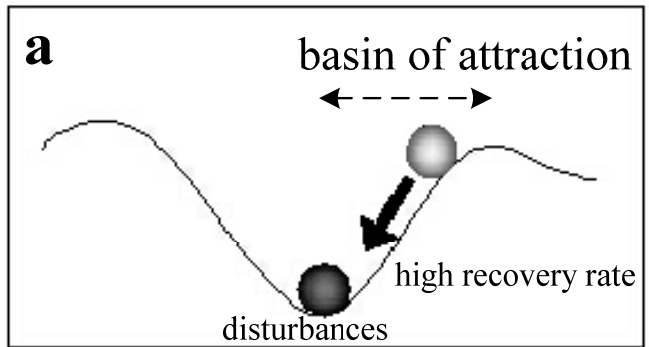

disturbances
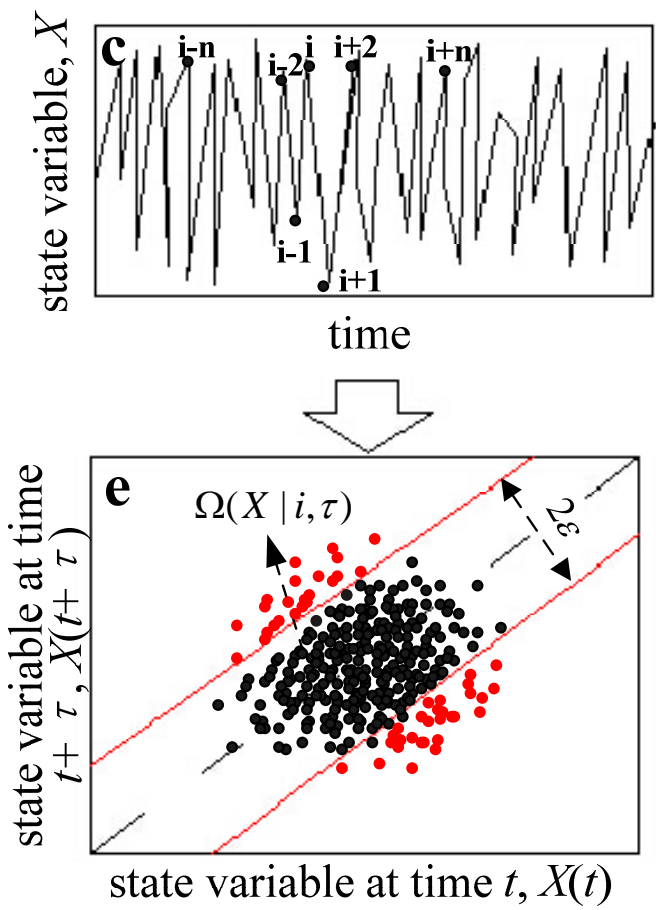

\section{low resilience}
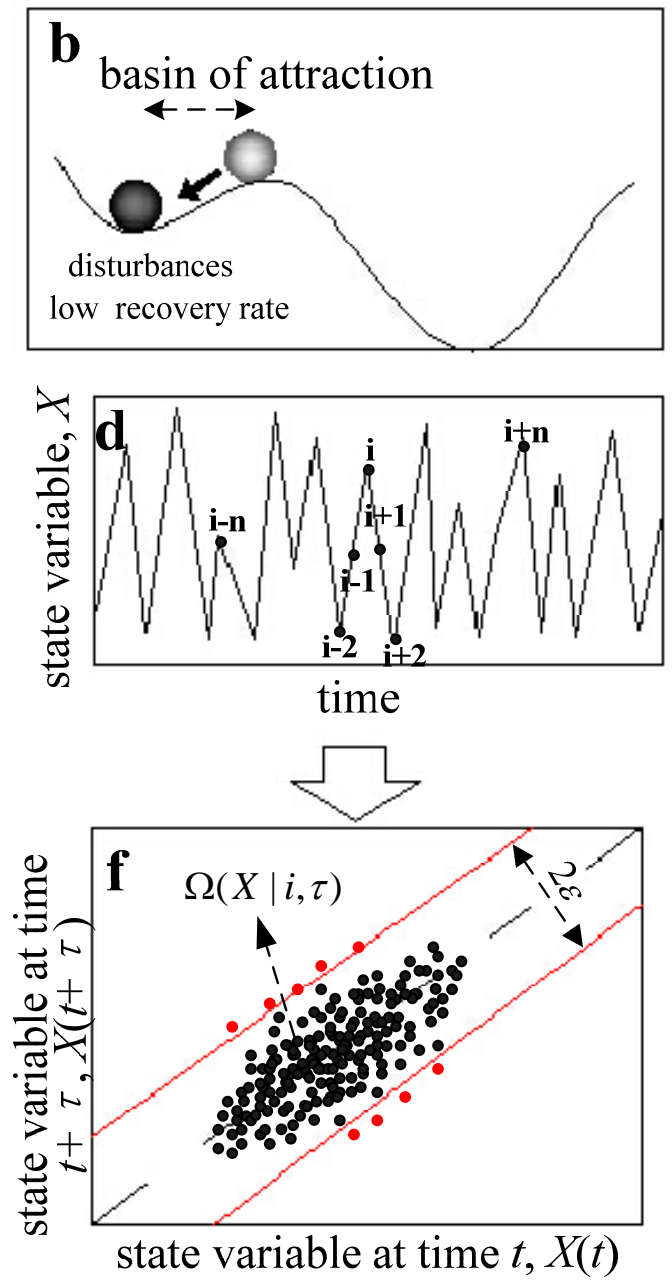

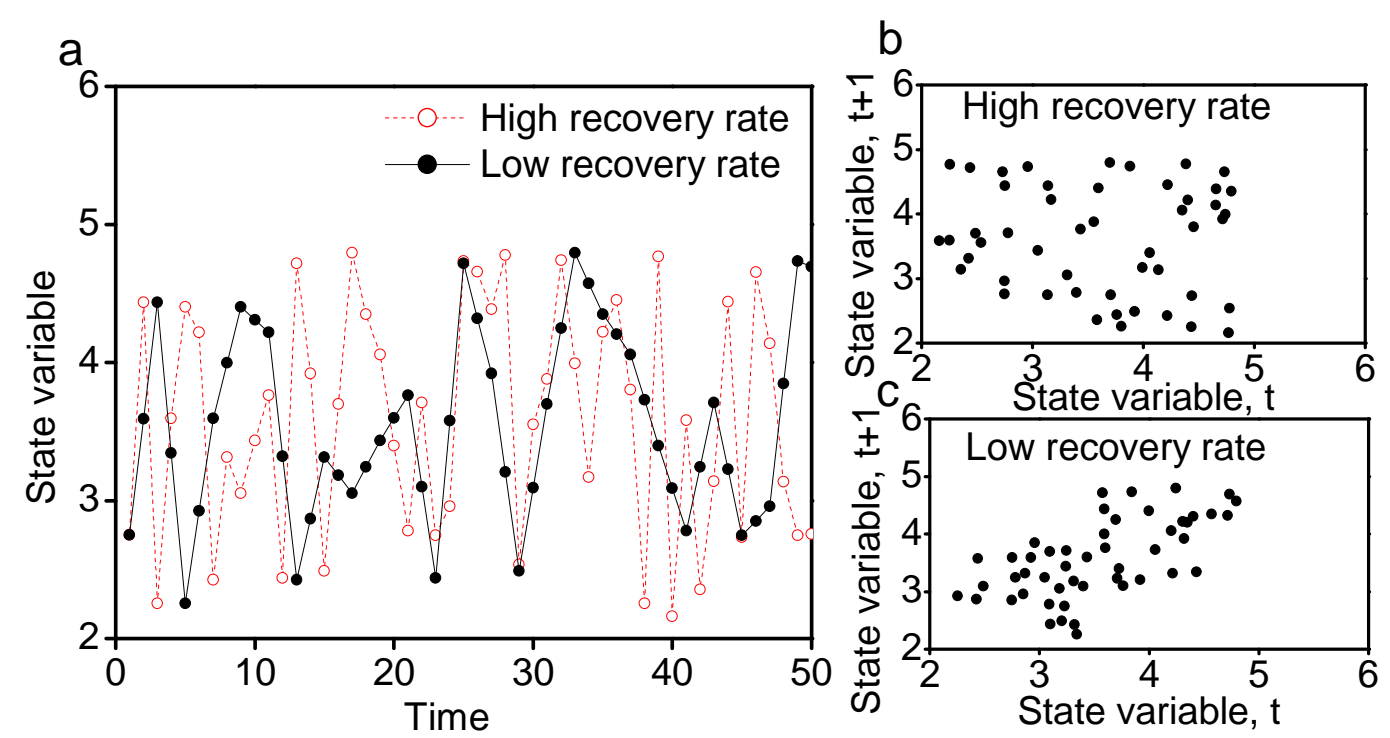

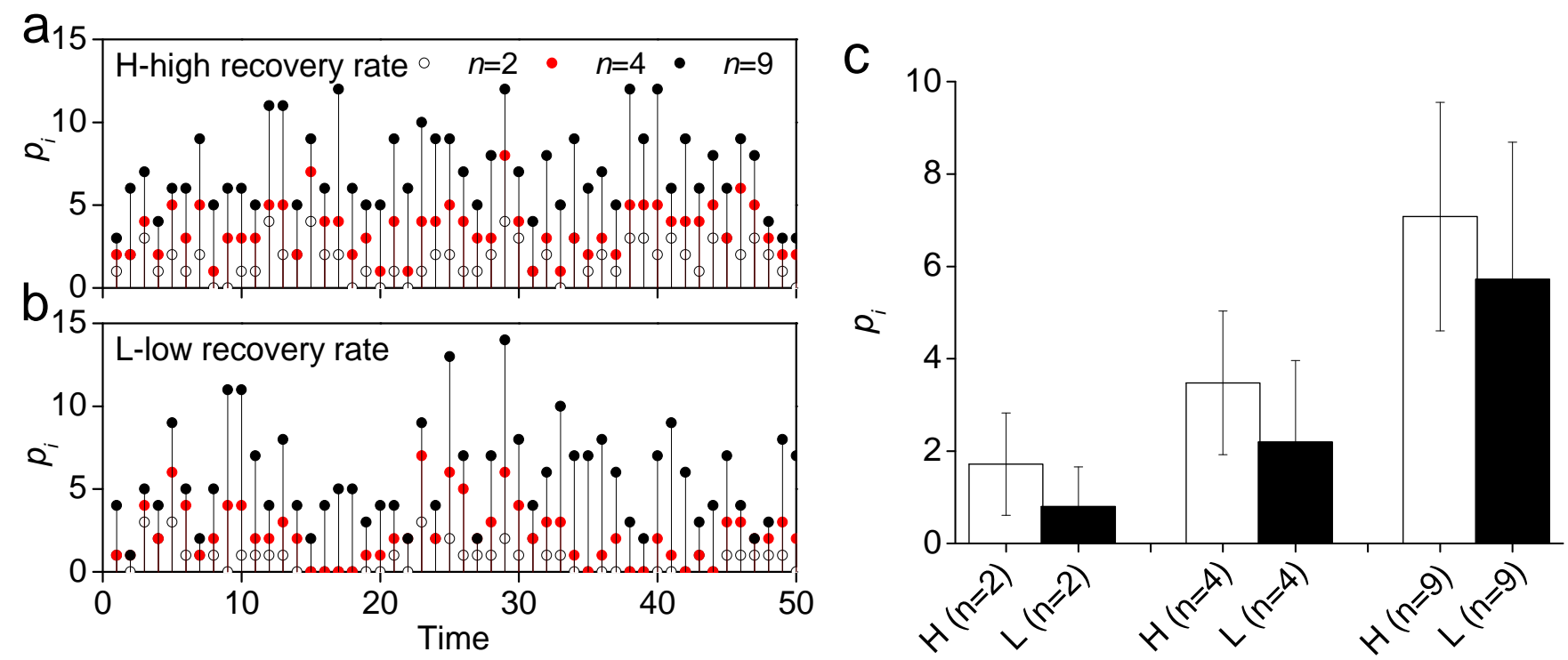


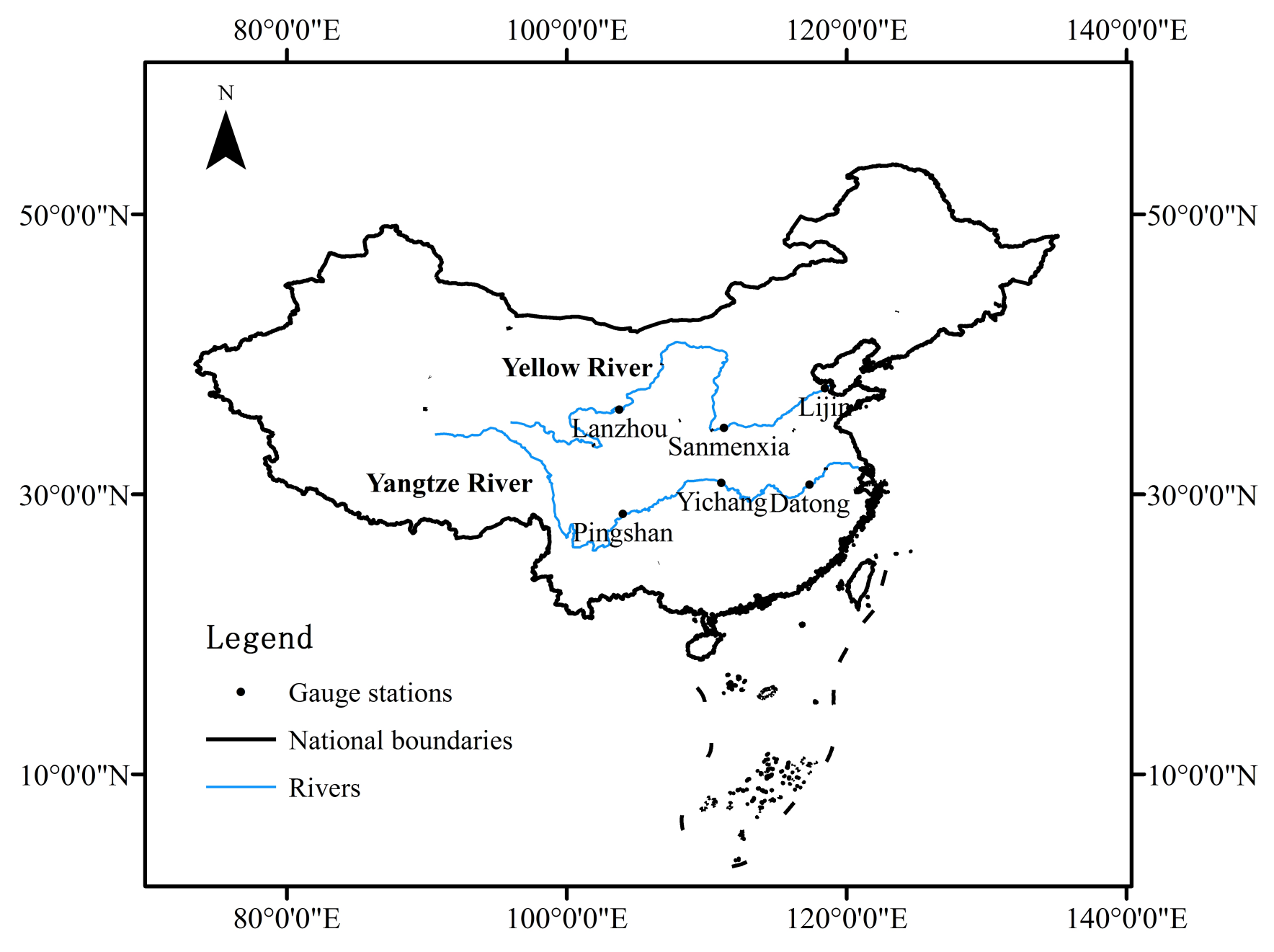



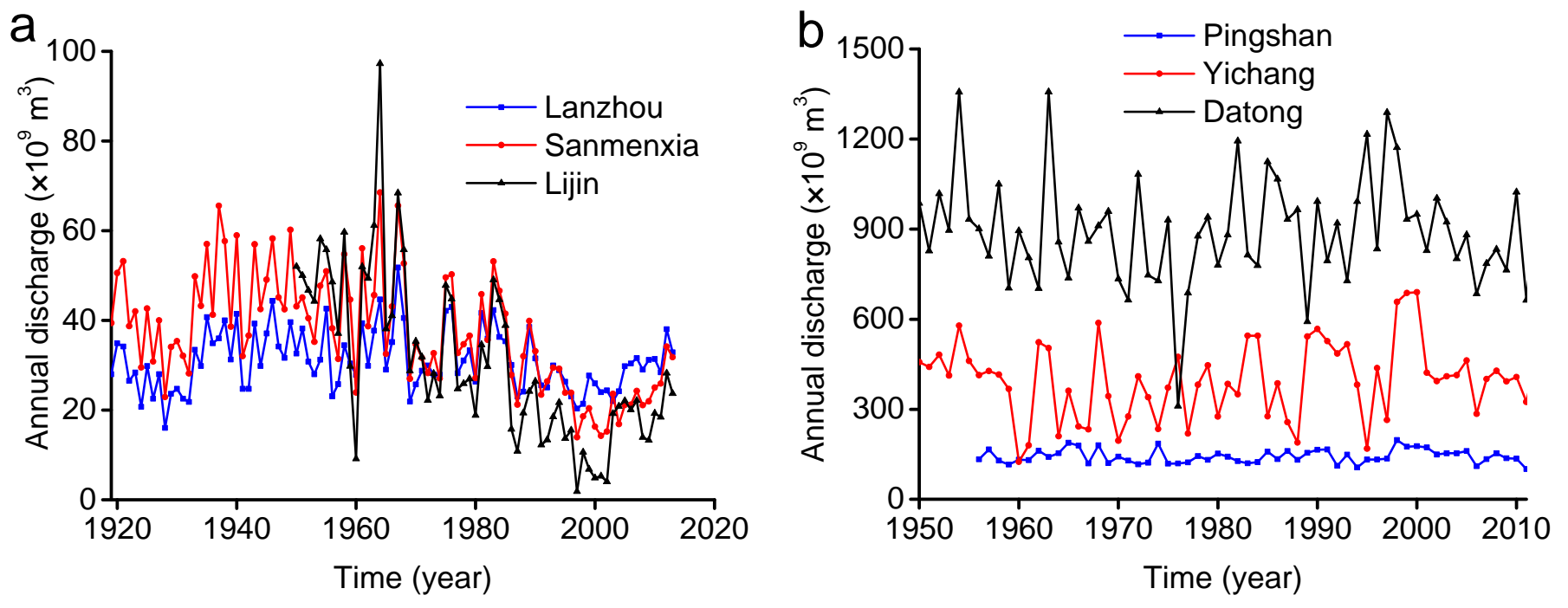


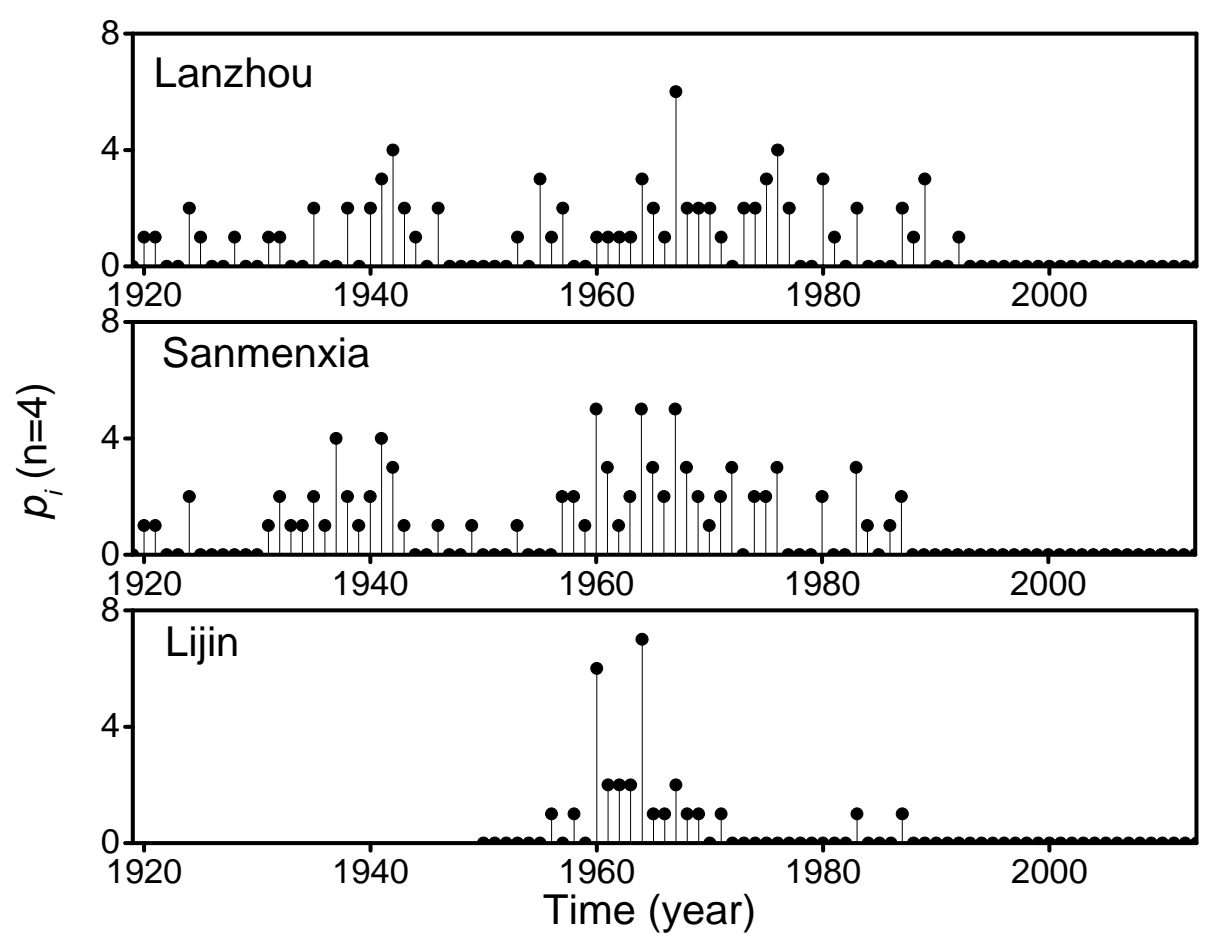




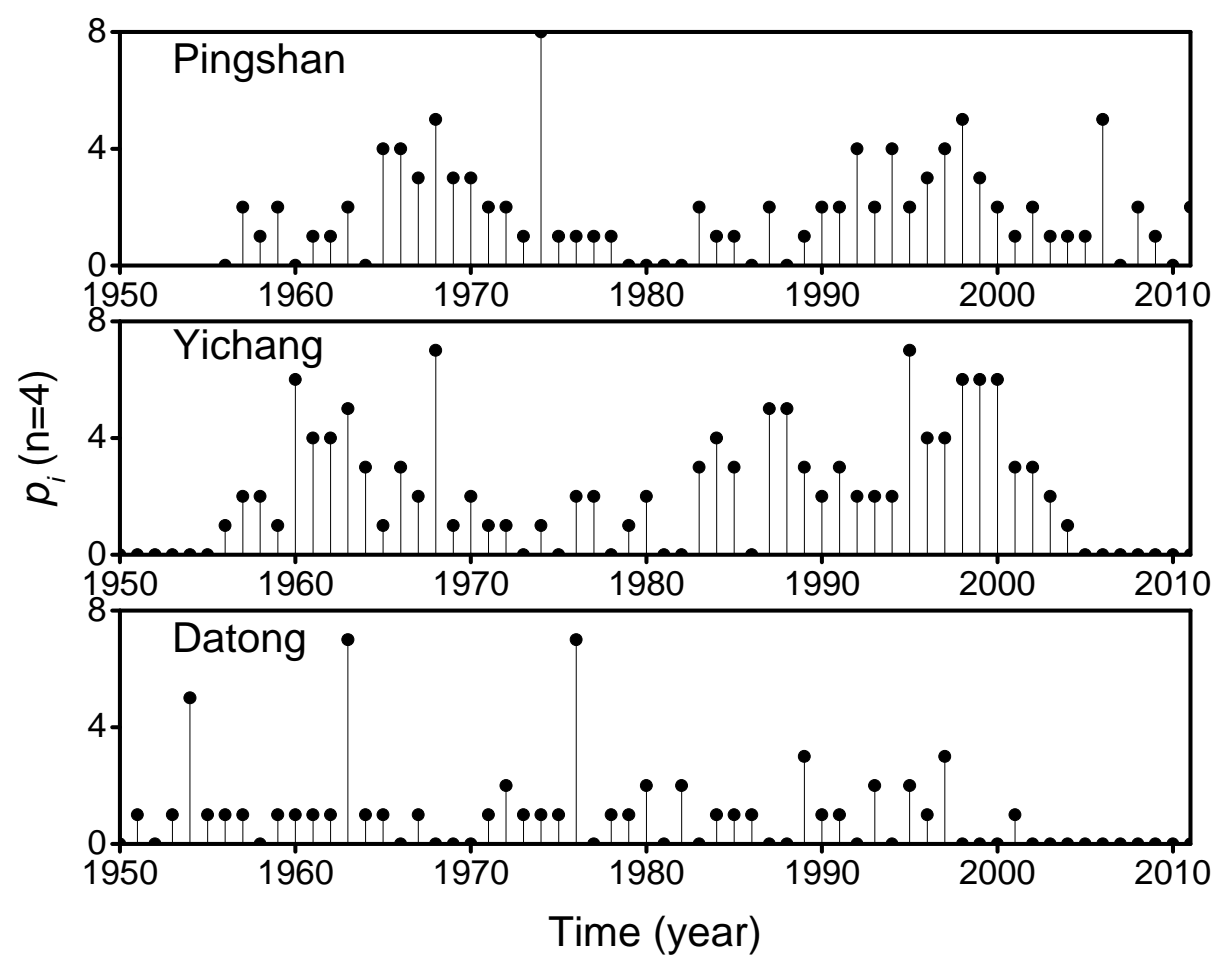



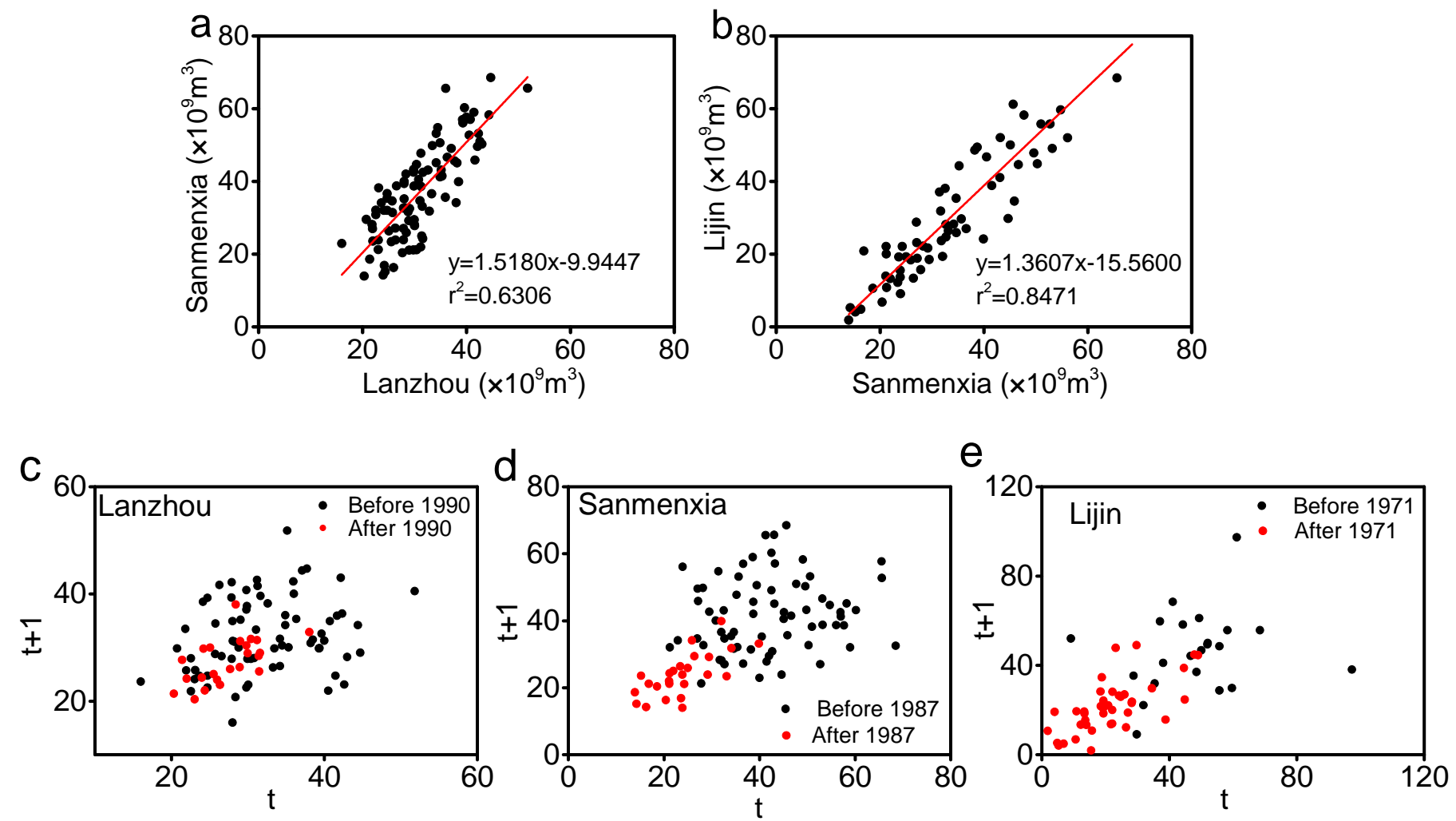

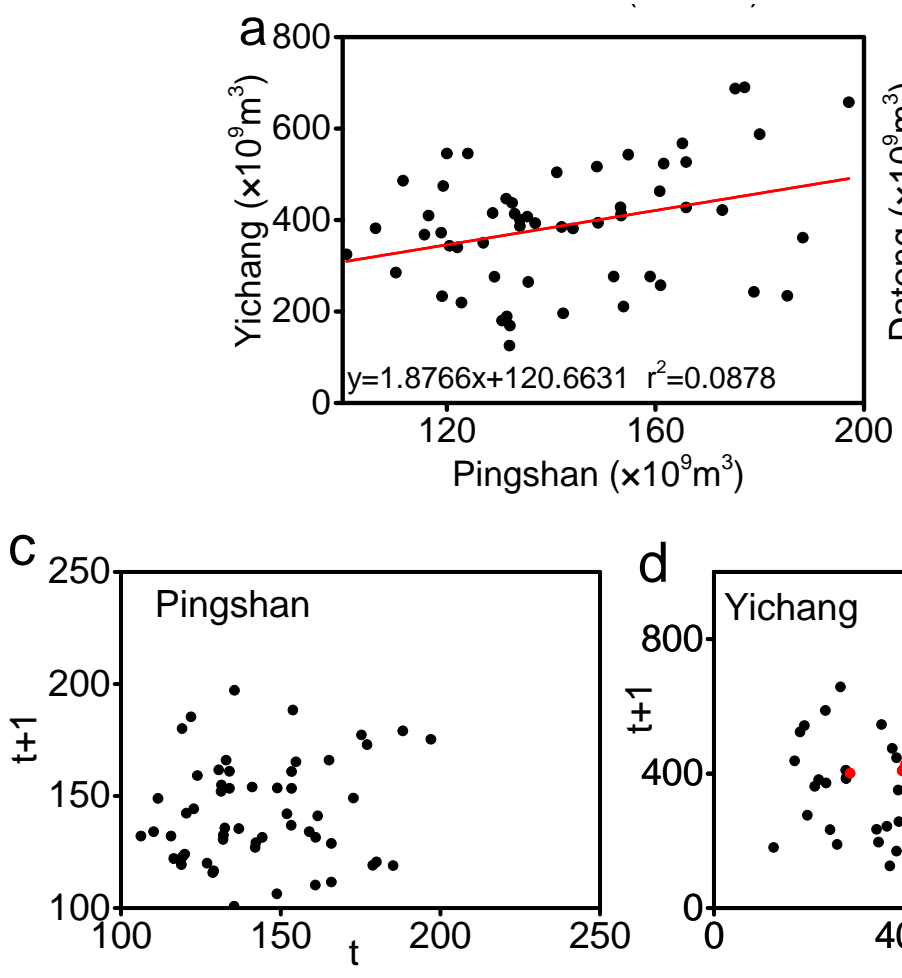
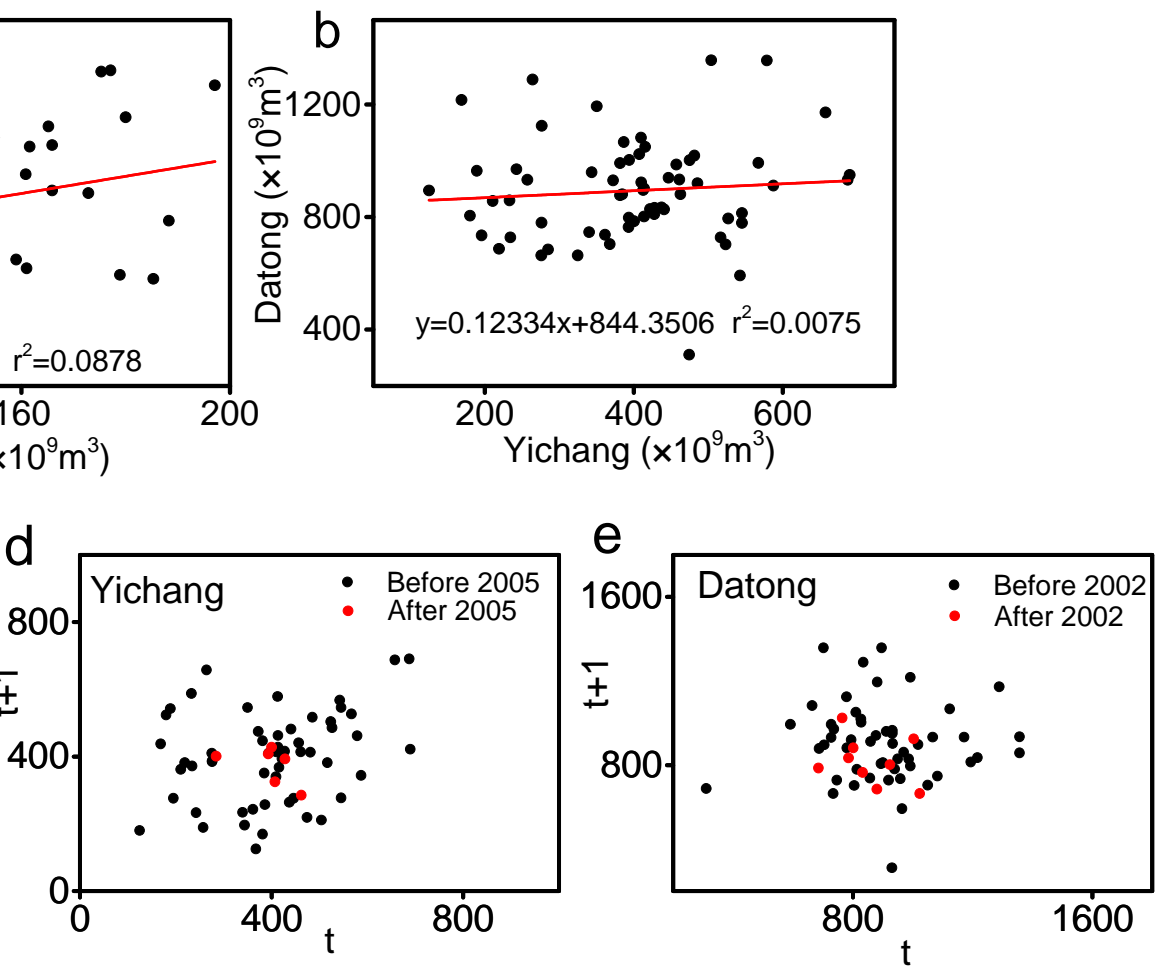

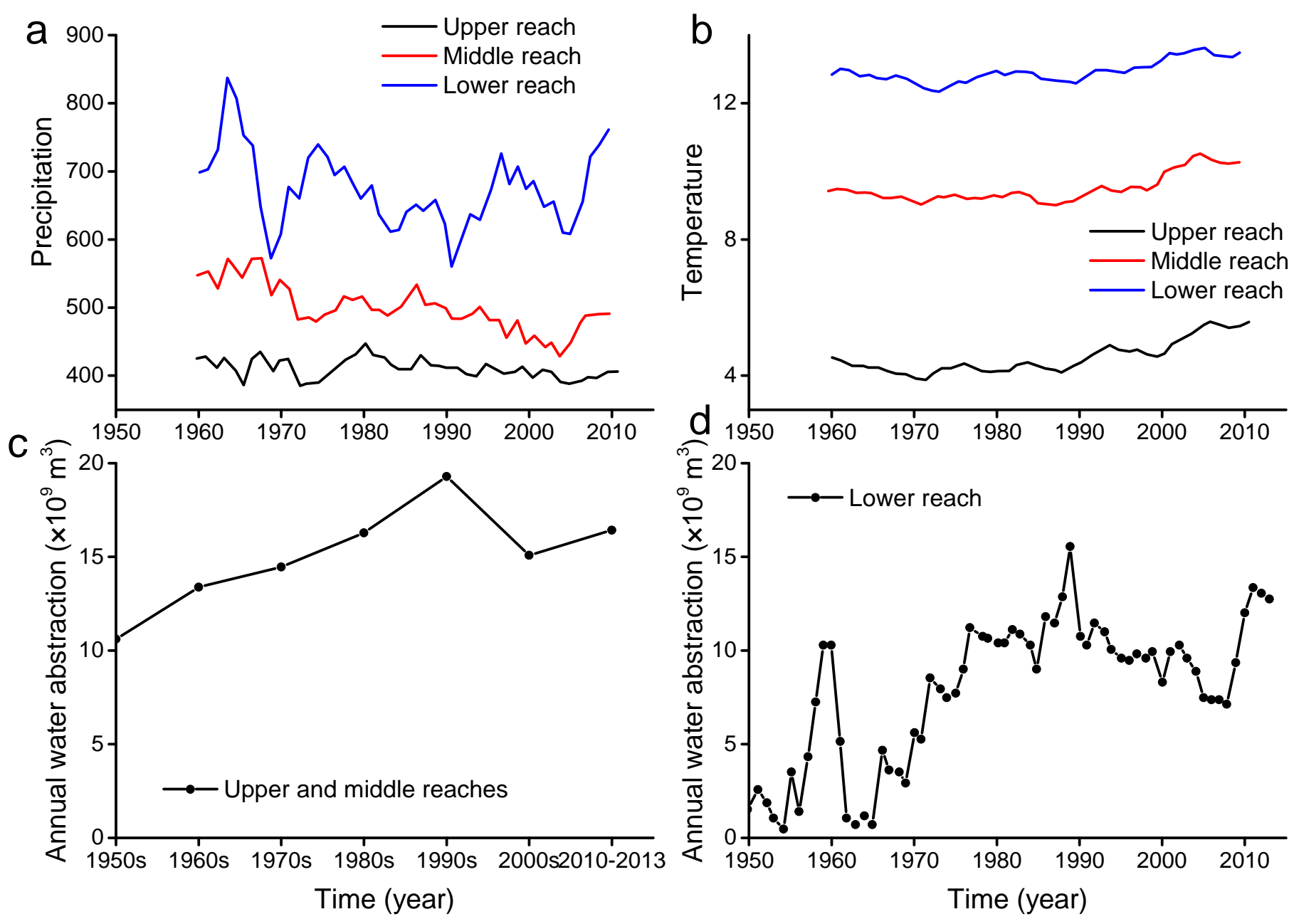